\title{
INCOME-SPECIFIC INFLATION RATES AND THE EFFECTS OF MONETARY POLICY: THE CASE OF NORTH MACEDONIA
}

\author{
Biljana Jovanovic ${ }^{1}$ \\ National Bank of the Republic of North Macedonia \\ petkovskab@nbrm.mk \\ Marko Josimovski \\ National Bank of the Republic of North Macedonia \\ josimovskim@nbrm.mk
}

\begin{abstract}
In this paper, we investigate the effects of monetary policy concerning the inflation rates specific for each income group of households. We find that the prices specific for high-income households are generally more rigid and less volatile compared to the prices specific for middle and lower-income households. This means that monetary policy can differently affect the different inflation rates specific for each of the income groups. By using a FactorAugmented VAR (FAVAR) model, we show that a monetary policy shock affects high-income households less compared to middle and lower-income households, although the differences between the separate income groups are generally small. Then, by using a small scale gap model, we find that the prices of low-income households are the most sensitive to a monetary policy shock, while the prices of the top-income households are the least sensitive to the shock, which is in line with our empirical findings.
\end{abstract}

Keywords: Inflation, monetary policy, distributional effects.

JEL Classification Numbers: E31, E52.

\footnotetext{
${ }^{1}$ The views expressed in this paper are those of the authors and do not necessarily represent the views of the National Bank of the Republic of North Macedonia.
} 